\title{
Da clínica à cultura: desdobramentos da pesquisa entre psicanálise e arte
}

\section{From clinical practice to Culture: unfoldings between Psychoanalysis and Art}

\section{De la clínica a la cultura: desdoblamientos de la investigación entre psicoanálisis y arte}

\author{
Ana Lúcia Mandelli de Marsillac* \\ Universidade Federal de Santa Catarina - UFSC, Florianópolis, Santa Catarina, Brasil
}

Gerusa Morgana Bloss**

Universidade Federal de Santa Catarina - UFSC, Florianópolis, Santa Catarina, Brasil

Thiciara Mattiazzi***

Universidade Federal de Santa Catarina - UFSC, Florianópolis, Santa Catarina, Brasil

\begin{abstract}
RESUMO
Este artigo propõe resgatar fragmentos do método psicanalítico no seu encontro com o campo das artes. A partir das contribuições de Sigmund Freud, Jacques Lacan, Georges Didi-Huberman e outros analistas contemporâneos, refletirá sobre as interfaces do método psicanalítico que partem do campo da clínica e se desdobram sobre o campo da cultura. Além disso, sublinhará as proximidades do fazer do analista e do artista, em uma contribuição ao campo da ciência e produção de conhecimentos. Ao afastarse dos princípios da linearidade, imparcialidade, generalização propostos pela ciência, os saberes psicanalíticos e artísticos permitem aprofundamento metapsicológico. O encontro entre psicanálise e arte nos aproxima das singularidades, das formas de dizer e de interpretar a cultura. O inconsciente como pedra angular, bem como os conceitos de significante, sujeito, sintoma e contingência são fundamentais nessa perspectiva metodológica, em suas análises clínicas e culturais. Eles contribuem na demarcação do método da psicanálise e dialogam com o campo das artes.
\end{abstract}

Palavras-chave: psicanálise, arte, cultura, saber e método.

\begin{abstract}
This article aims to recover historical fragments of the psychoanalytic method in its encounter with the Arts field. Considering Sigmund Freud, Jacques Lacan, Georges Didi-Huberman, and other contemporary analysts' contributions, it will ponder on the psychoanalytic method borders that which start on the clinical practice to unfold on culture's field. In addition, it will emphasize the proximity of the analyst's and the artist's makings, while contributing to the field of science and knowledge production. By moving away from the principles of linearity, impartiality, generalization proposed by
\end{abstract}


science, psychoanalytic and artistic knowledge allow a deepening of metapsychology. The encounter between psychoanalysis and art brings us closer to the singularities, the ways of saying and interpreting culture. The unconscious as a cornerstone, as well as the concepts of signifier, subject, and symptom are fundamental in this methodological perspective, in clinical and cultural analysis. These concepts contribute to the demarcation of the psychoanalysis method and dialogue with the field of the arts.

Keywords: psychoanalysis, art, culture, knowledge and method.

\section{RESUMEN}

Este artículo se propone rescatar fragmentos del método psicoanalítico en su encuentro con el campo de las artes. A partir de las contribuciones de Sigmund Freud, Jacques Lacan, Georges Didi-Huberman y otros analistas contemporáneos, reflexionará sobre las interfaces entre el método psicoanalítico, que parte del campo de la clínica y se desdobla sobre el campo de la cultura. Además, subrayará las cercanías del hacer del analista y del artista, en una contribución al campo de la ciencia y producción de conocimientos. Al alejarse de los principios de la linealidad, imparcialidad, generalización propuestos por la ciencia, los saberes psicoanalíticos y artísticos permiten profundización metapsicológica. El encuentro entre psicoanálisis y arte nos acerca a las singularidades, a las formas de decir e interpretar la cultura. El inconsciente como piedra angular, así como el concepto de significante, sujeto, síntoma y contingencia son fundamentales en esa perspectiva metodológica, en sus análisis clínicas y culturales. Ellos contribuyen en la demarcación del método del psicoanálisis y dialogan con el campo de las artes.

Palabras clave: psicoanálisis, arte, cultura, saber y método.

O próprio poeta gosta de reduzir a distância entre o que lhe é singular e a essência humana em geral; ele nos assegura, com frequência, que em cada um existe um poeta e que o último poeta deverá morrer junto com o último homem. (Freud, 1908/2015a, pp. 53).

A psicanálise é por excelência uma prática clínica, mas se desdobra para além dela na medida em que pensa o sujeito e sua relação com a cultura, com a sociedade e a história. Na proposição de 9 de outubro de 1967, Lacan argumenta sobre questões relativas à formação do analista e indica duas formas de articulação da psicanálise: extensão e intensão. A primeira relaciona-se ao desejo do analista e sua função de escuta no campo clínico e a segunda condiz com um enfoque em questões "que envolvem uma prática psicanalítica que aborda o sujeito enredado nos fenômenos sociais e políticos, e não estritamente ligado à situação do tratamento psicanalítico" (Rosa, 2004, p. 331).

Partindo das possibilidades de articulação da psicanálise em extensão, buscamos discutir as interações da psicanálise com a arte e a inserção desse cruzamento na sustentação de pesquisas acadêmicas e leituras da cultura. Analisaremos a psicanálise como 
método que se diferencia das formas clássicas de se fazer pesquisa. Sustentada pelo rigor que Ihe é próprio, calcado na ética do sujeito, a pesquisa em psicanálise não busca generalizações, mas experiências singulares e exemplares de um tempo.

A precariedade que qualifica o humano e seus saberes sustenta a necessidade de encontro com outros campos. No texto "A questão da análise leiga: conversações com uma pessoa imparcial" Freud (1926/1976a) já sustentava que a psicanálise não deveria ficar restrita aos consultórios médicos, pois seu alcance era maior, pelo diálogo que travava entre clínica, cultura e história.

Seja como for, seria errôneo sacrificar todas as outras aplicações a essa única, só porque diz respeito ao círculo de interesses médicos. Se historiadores da civilização, psicólogos da religião, filósofos e assim por diante concordassem em manejar o novo instrumento de pesquisa que está a seu serviço. O emprego da análise para o tratamento das neuroses é somente uma das suas aplicações; o futuro talvez demonstre que não é o mais importante. (Freud, 1926/1976a, pp. 280)

Freud, ao criar o conceito de inconsciente, aprofunda a ferida narcísica humana e contribui ao campo das ciências humanas com um conhecimento revolucionário. O Eu não é senhor em sua própria casa (Freud, 1933/1992d). O inconsciente é a pedra angular da psicanálise, ponto de diferenciação entre outras teorias psicológicas e filosóficas. Até Freud "descobri-lo", enquanto um sistema psíquico com princípios e organização específica, ele tinha apenas uma perspectiva adjetiva, sendo o contrário do consciente (Loparic, 1991). A escuta do inconsciente tem consequências que permitem a construção da metapsicologia, também conhecida por psicologia profunda. Esta busca avançar em relação à nosologia, que visa, sobretudo, a classificação das doenças; para uma perspectiva de análise dinâmica, econômica e topológica (Roudinesco, 2009).

Dessa forma, este artigo objetiva recuperar alguns conceitos que nos permitam percorrer os desdobramentos da pesquisa entre psicanálise e arte. Baseamo-nos nas contribuições de Sigmund Freud e as colocamos em diálogo com análises de Jacques Lacan e outros psicanalistas contemporâneos que têm se ocupado das relações entre esses campos de saberes. Resgataremos também as discussões estabelecidas pelo filósofo e historiador da arte Georges DidiHuberman, que tem articulado seu trabalho no campo das artes com ênfase no saber psicanalítico e no pensamento de Walter Benjamin e Michel Foucault.

Estruturamos a discussão deste artigo em três eixos. O primeiro analisa as aproximações entre psicanálise e ciência. Posteriormente, será enfatizado o diferencial do método da psicanálise e seus 
aspectos históricos, que partem da experiência clínica e se debruçam sobre os traços da cultura. Neste eixo, destacaremos conceitos e elementos fundamentais que envolvem o método psicanalítico tais como: o inconsciente, o significante, o sujeito - objeto, a contingência e o sintoma. Em um terceiro eixo, tecemos aproximações entre psicanálise e arte e seus métodos. Nossas considerações finais analisam as contribuições dessa aproximação de campos de saberes e seu diferencial na produção de conhecimento contemporâneo.

\section{Método}

O método de construção desse artigo é o psicanalítico e teve como objeto de análise as articulações entre arte e psicanálise. Abarcou análise dos pressupostos do método da psicanálise na inter-relação entre clínica e cultura, tendo como eixo as contribuições de Sigmund Freud. Cabe destacar que não trabalhamos, no campo da psicanálise, com a proposta de uma metodologia (Lacan, 2016), pois esta pressuporia uma forma padrão de pesquisar. Sustentamos, a partir das análises de Freud e Lacan, que se trata de um método, que tem princípios epistemológicos, éticos e políticos, mas que se estende de forma singular a cada objeto sobre o qual se debruça.

Objetivamos aprofundar nesse artigo os diálogos deste método, no que diz respeito ao campo das artes. Assim, sublinhamos as contribuições de Jacques Lacan, Georges Didi-Huberman, psicanalistas e pesquisadores dessa interface na contemporaneidade. Ao longo dessa discussão, são realizados cruzamentos entre métodos e princípios da psicanálise e da arte.

Salientamos que os elementos históricos destacados não terão um caráter de linearidade, pois essa contrapõe-se à perspectiva psicanalítica. Dessa forma, indicamos que se tratam de inscrições do método, que se complementam como um turbilhão, criando uma dimensão anacrônica das análises, onde o que temos no presente relê o passado, recria-o, sem deixar, contudo, de seguir os faróis que a obra freudiana dá a ver.

\section{Discussão}

\section{Psicanálise e Ciência: Algumas Perspectivas}

Em meio a um contexto de grande euforia com relação à ciência, nasce a psicanálise. Sigmund Freud, considerado o pai da psicanálise, inicia sua formação como médico neurologista, estudioso dos mecanismos psíquicos. Em 1885, aprofundou seus estudos sobre as doenças dos nervos na Salpêtriere (Rubin, 2011), deparando-se com 
um hospital no qual estavam internadas cerca de 4000 pessoas (Kapinist \& Roudinesco, 1997), sobretudo mulheres, acometidas pela histeria. Freud acompanha os métodos de tratamento pautados na hipnose, nos banhos, camisas de força e, até mesmo, intervenções cirúrgicas, que se revelavam pouco eficazes.

Apreciador de literatura, arte, antropologia e história, valia-se desses saberes e os colocava em diálogo com a medicina para seus estudos metapsicológicos. Chegou a encantar-se, como bem analisa DidiHuberman em seu livro: "Charcot a iconografia fotográfica da Salpêtriere" (2015), pela produção de imagens fotográficas conduzida por Charcot. Mas a fixação das imagens seguia em um rumo distinto do pensamento freudiano, que já refletia nesse período sobre os limites da generalização no campo psíquico. A relação com a imagem fotográfica e a fábrica de imagens alavancada por Charcot visava o aprofundamento do conhecimento e padronização sobre a histeria. Registro que buscava assegurar e criar verdades, estereótipos dos modos de sofrer. Para Freud, começavam a ficar claros os limites desse conhecimento.

Foi a partir da escuta dos sintomas histéricos que Freud pôde vislumbrar os fenômenos da divisão psíquica, que o levaram à descoberta do inconsciente. A teoria da fantasia, do traumático e do inconsciente teceram o caminho da singularidade. O método que ele desenvolveu não perde rigor, mas pauta-se sobre outros princípios, para além de uma nosografia dos sintomas (Roudinesco, 2009). Levando a fundo a hipótese do inconsciente, Freud (1915/1992b) cria um método de análise do sofrimento psíquico que se complementa em três perspectivas do aparelho psíquico: dinâmica (análise das relações entre os sistemas psíquicos e a relação com os outros), econômica (análise do quantum de libido investido em cada um dos sistemas) e topológica (análise das estruturas psíquicas). Sustenta a regra fundamental da livre associação, como via de acesso ao inconsciente e a indispensável neutralidade do analista, que implica em não realizar julgamentos morais e não atuar por sugestão. Essas premissas relacionam-se diretamente a uma concepção ética que envolve a radical singularidade de cada caso, ainda que a partir de princípios estruturais da subjetividade.

A descoberta freudiana recebeu muitas críticas, principalmente quanto a sua cientificidade, mas Freud frequentemente esteve alinhado aos critérios científicos e ligado à ciência. É por essa perspectiva que fez sua formação e buscou sustentar a teoria e o método, que criou. Ainda que ligado aos ideais cientificistas de sua época, seu contato com as pacientes histéricas aproximou-o de sintomas psíquicos complexos, que resistiam aos saberes existentes e levaram-no à hipótese da divisão psíquica e do inconsciente. Consequentemente, Freud introduz a radical diferença entre a concepção de verdade para o saber científico e para a psicanálise. 
Tal descoberta altera radicalmente as noções de subjetividade e de sujeito vigentes e questiona o campo do saber e da experiência do homem. Lacan (1998) analisa que Freud não rompeu com o cientificismo de sua época, mas que foi por essa mesma via que ele inaugurou a psicanálise. $O$ debate sobre a cientificidade da psicanálise é extenso e bastante contemporâneo. Poderíamos dizer que a centralidade dessa discussão é pautada sobre duas distinções importantes: entre realidade e razão e entre saber e verdade. A psicanálise justamente questiona a ciência, pois esta coloca suas análises na ordem de um indivíduo, indivisível, ao passo que a psicanálise anuncia o sujeito por sua divisão (Dunker, 2017).

Temos aí um eixo central: o sujeito como questão. Lacan (1998), resgatando os ensinamentos freudianos, argumenta que "não há ciência do homem [...] porque o homem da ciência não existe, mas apenas seu sujeito" (p. 873). Na suposição de neutralidade e objetividade, próprias do saber científico, exclui-se a dimensão não toda daquele que anima a pesquisa. Cabe destacar, que o sujeito do desejo busca saber mais, a partir do mal-estar que o habita. 0 homem, que faz ciência e que é objeto da ciência, é habitado pela incompletude e caracterizado pela divisão psíquica. É sobre esse sujeito que a psicanálise se ocupa, tendo o inconsciente como seu objeto de pesquisa privilegiado. Conforme Jacques Lacan, esta é uma diferença importante entre ciência e psicanálise.

E lembramos que se, certamente, levantar agora a questão do objeto da psicanálise é retomar a questão que introduzimos a partir de nossa vinda para esta tribuna, pela posição da psicanálise, dentro ou fora da ciência, indicamos também que essa questão não pode ser resolvida sem que, sem dúvida, modifique-se nela a questão do objeto na ciência como tal. (Lacan, 1998, pp. 877).

Então, pode-se pensar que a psicanálise está dentro e fora da ciência. Dentro, no sentido de que ela produz conhecimentos fundamentais sobre a metapsicologia, contribuindo de forma consistente no campo da saúde mental e nos meios acadêmicos e institucionais, onde há um rigor científico e critérios a serem seguidos. Mas também está fora porque não se alia aos mesmos pressupostos clássicos da ciência e até mesmo os questiona.

Os objetos, na perspectiva que teoriza a psicanálise, não são independentes daquele que se ocupa deles. Dessa forma, o desejo do pesquisador, que busca saber mais, ou do analista, que busca colocar em análise, está sempre em jogo. Há uma relação direta entre o desejo de saber mais e a relação transferencial com o tema, uma vez que se investe libido em busca do prazer de saber mais (Freud, 1915/1976b). 
O objeto, para a psicanálise (Lacan, 1995), é tudo aquilo que não é o sujeito, mas com os quais ele se identifica de alguma forma. Os objetos, nesse sentido, podem ser: outro sujeito, um fato, um monumento, uma obra; eles portam uma verdade sobre si, sobre a qual o pesquisador busca saber mais. Neste gesto, o pesquisador agrega a si e à cultura saber sobre o outro, contribui à sua verdade enquanto sujeito; mas esta verdade, enquanto saber inconsciente, mantem-se como enigma e o relança a novos objetos. Essa perspectiva rompe com a suposta neutralidade da ciência, que crê poder não se envolver com o objeto a ser pesquisado.

Freud nos indica que o objeto é apreendido pela via de uma busca do objeto perdido (...) uma nostalgia liga o sujeito ao objeto perdido, através da qual se exerce todo o esforço da busca. (...) É através da busca de uma satisfação passada e ultrapassada que o novo objeto é procurado, e que é encontrado e apreendido noutra parte que não no ponto onde se o procura. (Lacan, 1995, pp. 13)

Avançando sobre o aspecto do objeto, Lacan (1998) indica ainda que a ciência pressupõe a verdade como causa, tomada como causa formal, ao passo que a psicanálise enfatiza o aspecto de causa material, colocando o significante se sobrepondo ao significado. Nesse sentido, aproxima-se de um método de pesquisa estrutural, que se ocupa dos objetos por sua perspectiva significante.

Cabe destacar, dessa forma, que um princípio fundamental em relação ao método diz respeito à inclusão do sujeito em qual seja a temática, ou a atividade da psicanálise: "Na psicanálise, há, isto sim, um 'campo de pesquisa', que é o inconsciente, e que inclui o sujeito. Por isso, a clínica, como forma de acesso ao sujeito do inconsciente, é sempre o campo de pesquisa" (Elia, 2000, p. 23). Qualquer problemática a ser investigada irá requerer que 0 analistapesquisador direcione sua escuta, sempre clínica, ao que deseja saber, sempre na condição de parcialidade e principalmente abarcando a diferenciação entre o saber e a verdade. Quando dizemos que uma pesquisa é clínica, não estamos nos referindo ao espaço físico do consultório, mas de uma ética do sujeito que se desloca para qualquer atividade do psicanalista.

\section{Da Clínica à Cultura}

Trata-se de uma afirmação de Freud (1912/1992a), no seu artigo: "Recomendações aos médicos que exercem a psicanálise", o fato de que pesquisa e tratamento coincidem, quando se fala em psicanálise, pois, ao considerar a radical singularidade de cada caso, a pesquisa sobre essa subjetividade específica se desdobra paulatinamente à 
condução do tratamento. Como bem analisa Fernando Aguiar (2006), no artigo "Questões epistemológicas e metodológicas em psicanálise", a psicanálise pode ser conceituada, antes de tudo, como um método interpretativo.

Esse é pautado no rigor teórico, que parte do conceito de inconsciente. Para termos acesso a ele, tanto no campo da clínica quanto na análise da cultura, cabe resgatar a regra fundamental da associação livre, que permite fazer furo no discurso consciente, acessando aquilo que são as formações do inconsciente e suas manifestações discursivas por meio do que se repete, o que parece fora de lugar. A base das interpretações parte do material que se destaca na associação livre e também tem como pressupostos a relação transferencial com o sujeito que se escuta ou o objeto ao qual se pesquisa e a atenção/escuta flutuante por parte do analista.

As formações do inconsciente trabalhadas por Freud, tais como os sonhos, os atos falhos, os chistes, os lapsos e os sintomas (Freud, $1915 / 1992 b)$ demonstram o quanto somos determinados pelos mecanismos psíquicos. O inconsciente fala por suas formações para além do que o eu da consciência idealize. As obras de arte também podem ser pensadas como manifestações do inconsciente, mas em uma relação que extrapola a singularidade do artista e se enlaça com o outro que se dispõe a ver, em um campo sustentado pela cultura (Didi-Huberman, 2015). Aproximam-se, dessa forma, os sintomas, enigmas de um tempo, que o artista expõe a público.

Essa perspectiva também vem sendo conceituada no campo das artes, a partir da discussão que a arte contemporânea tem colocado em causa. Marcel Duchamp (1965/1986) auxilia-nos nessa reflexão ao analisar que sempre haverá uma diferença entre o que o artista quis realizar e o que realmente realizou. Depara-se, assim, com a questão do inconsciente que está implicada na realização do ato criador, revelando que a obra extrapola a intenção consciente do autor.

Nesse sentindo, podemos pensar no público fazendo parte do ato criador. Nas palavras do autor: "no ato criador, o artista passa da intenção à realização, através de uma cadeia de reações totalmente subjetivas. Sua luta pela realização é uma serie de esforços, sofrimentos, satisfações, recusas, decisões que também não podem e não devem ser totalmente conscientes, pelo menos no plano estético" (p.1). Entre artista e sua criação, público e obra há um vazio, um para além do que pode ser colocado em palavras, que remete à dimensão do inconsciente, e que Duchamp denomina de coeficiente artístico.

Essas breves aproximações entre princípios metapsicológicos e artísticos revelam que esses dois campos de saber não partilham, com o saber científico, a lógica causal linear de pensamento, tampouco a perspectiva da imparcialidade do pesquisador. Arte e 
psicanálise são fazeres que tem princípios estruturais, mas se modulam no ato de fazer (Brites, 2002). Suas produções expõem o envolvimento do inconsciente, a parcialidade e singularidade da tomada de posição e leitura da cultura.

A discussão teórica que abrange o sujeito do inconsciente é uma contribuição de Lacan, que revisita as análises iniciadas por Freud, e envolve a manifestação fugaz, como um lampejo desse sujeito que se articula com o eu. O inconsciente (Freud, 1915), o insabido (do alemão Das Unbewusste), assim, ocupa um papel central, ao mesmo tempo em que ele se mantém inconsciente, conforme sugere 0 próprio nome. Dessa maneira, ao mesmo tempo em que se manifesta, nunca se chegará a um saber total sobre ele, a uma elucidação completa de seu funcionamento. Isso quer dizer que é possível nos aproximarmos dele através de seus efeitos e que ele, ainda assim, se mantém enigmático. Outra maneira de esclarecermos essa questão é a consideração de que só temos acesso ao inconsciente pela consciência, quando seus efeitos se manifestaram ao passar pelo recalque.

Freud (1915/1992b) afirma que tanto o físico quanto o psíquico não são necessariamente o que parecem ser. Ele faz essa elaboração no texto O inconsciente (1915/1992b), ao comparar a percepção dos processos mentais inconscientes (que não são inconscientes em si mesmos) à percepção do mundo externo pela sensorialidade. Nessa mesma elaboração, Freud retoma a ideia kantiana de que as nossas percepções são subjetivamente condicionadas e, a partir disso, ressalta que as percepções adquiridas pela consciência e pelos processos inconscientes não são equivalentes. Outra constatação nesse texto é de que os objetos internos (realidade psíquica) são menos incognoscíveis do que o mundo externo.

A realidade, nesse sentido, é vista através de um filtro, do inconsciente, sendo sempre, portanto, uma perspectiva subjetiva. Esse modo de pensar a realidade tem consequências consideráveis no modo que a psicanálise nos orienta a analisar a constituição subjetiva e a cultura. Partimos sempre da impureza do olhar do analista/pesquisador, que não consegue se despir por completo da sua subjetividade, do tempo que habita e da perspectiva que olha (Didi-Huberman, 2017, 1998). Ao mesmo tempo, a realidade da qual se ocupa seja ela no campo da clínica ou da cultura é complexa, multifacetada, habitada por uma verdade que desconhece e por um saber que a orienta.

O princípio da associação livre, crucial no método psicanalítico, permite que os tropeços da fala emerjam. O psicanalista dirige-se ao sujeito, supondo nele um saber, engendrado através dos significantes recalcados (elementos inconscientes), que emergem através das falhas da fala, dos sonhos, sintomas e da posição do sujeito no discurso (Calligaris, 2004). Estes significantes, neste ato, supõem o 
sujeito por eles representado. Nesse sentido, sustenta-se, a partir das contribuições de Lacan, que o inconsciente fala em meio ao discurso consciente, sustentando o que é dito permanentemente, ainda que se manifeste como uma pulsação.

A contrapartida da associação livre é a atenção/escuta flutuante. Tal pressuposto permite que toda fala do analisando seja investida com a mesma intensidade, sem que algo se sobreponha no momento da escuta (Freud, 1912/1992a). Trata-se de uma tentativa de análise do sujeito a partir do que emerge e não de recortes dados a priori.

$\mathrm{Na}$ clínica, podemos considerar que cada sujeito que está diante de nós apresenta-se como um estrangeiro, do qual nada sabemos. Em uma postura de interrogação, abstemo-nos de julgamentos, buscamos nos aproximar e colocar em questão o que constitui e estrutura a linguagem, o desejo, a singularidade de cada um. Também na pesquisa psicanalítica é preciso pautar-se nesses pressupostos, na qual a postura do pesquisador frente ao estudo será de abertura para a análise da singularidade discursiva do objeto em questão e de interrogação sobre o que o olha naquilo que vê (DidiHuberman, 1998).

Nesse sentido, a noção de a posteriori nos orienta no direcionamento da escrita, uma vez que, através da leitura flutuante das realidades, da temática, dos casos, das obras e objetos da cultura a serem analisados, busca-se refletir sobre as diferentes dimensões que emergem. É só em um segundo tempo que conseguimos elaborar o que experenciamos. Isso possibilita uma visão densa e, ao mesmo tempo, uma autorização frente ao que interroga diante do objeto de estudo. Assim, "o conhecimento psicanalítico dá-se, portanto, a posteriori - isto é, no sentido clássico, filosófico, como resultado da experiência ou dela dependente." (Aguiar, 2006, p. 111).

Seria equivocado afirmar que não há recortes anteriores que demarcam o olhar para a obra. Há transferência e teorização que sustentam o olhar e, por conseguinte, a escrita. A intenção, nesse caso, é poder dar um passo atrás e, colocando-se em segundo plano, permitir que a singularidade que está em análise revele sua força. Trata-se de um paradoxo: a rede simbólica sustenta o olhar do analista, porém, é em um segundo tempo que simbolizamos o que experenciamos.

Foi a partir do conceito de angústia que Freud chegou à dimensão da temporalidade própria ao sistema inconsciente (Loparic, 1991). Esse afeto, que tem dimensão central nas teorizações psicanalíticas, revela sua potência ao misturar os tempos, nos quais uma situação presente desperta uma lembrança do passado e uma antecipação do futuro. Esse cruzamento temporal diz da experiência subjetiva e envolve analista/analisando, pesquisador/objeto de pesquisa. Cabe sublinhar que o sistema inconsciente, segundo Freud (Freud, 1915/1992b), não 
é ordenado pelo tempo, uma vez que é regulado pelo processo primário.

Nesse sentido, o anacronismo, enquanto essa perspectiva não linear da história, onde não há simplicidade nas relações de causa e efeito e sim turbilhão (Didi-Huberman, 2017), orienta o fazer em psicanálise. Nas lembranças, nos mitos, nas obras de arte, nos traços da cultura a densidade do tempo se faz presente.

A obra, enquanto um corpo, um acontecimento (Didi-Huberman, 1998), institui-se em seu enodamento simbólico, imaginário e real no espaço: "O espaço implica o tempo" (Lacan, 2016, p. 56). Das três dimensões do espaço, o real é o registro que sublinha o tempo, pela contingência que o envolve.

Assim, a análise da contingência faz-se um dos princípios estruturais do método. Em um a posteriori, o analista reflete desde o tempo presente sobre as contingências que sustentam determinada singularidade, obra, fato, acontecimento. Essas contingências revelam a densidade de tempos envolvidos em um mesmo objeto, mas ao mesmo tempo demarcam um campo de possibilidades simbólicas e imaginárias, que envolvem as lógicas, tabus, mitos, fantasias e, paradoxalmente, demarcam um real como um impossível a ser simbolizado, algo inexorável, que não cessa de não se escrever (Lacan, 2016).

Buscamos, portanto, fazer uma leitura da cultura da mesma maneira que se articula a escuta na clínica: de forma que as significações possíveis sejam pensadas em um momento posterior, a partir do que surge enquanto questão desse olhar flutuante para a obra e da interrogação que a obra nos interpela. Nos propomos a perceber os significantes que se destacam na escuta clínica, mas também nos traços da cultura sobre os quais o analista se propõe a pesquisar. Segundo o crítico literário e teórico da cultura Fredric Jameson (1992), a interpretação se dá em um campo de batalha, onde muitos elementos estão dispostos e precisam ser considerados. "A interpretação não está aberta a todos os sentidos", diz Lacan (1964/1988, p. 236). Sendo assim, ainda que tenhamos muitos elementos a analisar, é preciso ter como nosso prumo o caso clínico ou a obra em sua radical singularidade.

O conceito de sintoma ganha toda sua força nesse ponto, pois ele indica a formação de compromisso entre diferentes instâncias subjetivas, que se articulam como forma de dar a ver uma realidade. Paradoxal e enigmática composição entre conteúdos manifestos e latentes, prazer e desprazer, singularidade e laço social.

Georges Didi-Huberman (2017) vem desenvolvendo análises que indicam a importância de pensarmos as obras de arte, os traços da cultura, como sintomas de um tempo. Assim, clínica e cultura se tocam, mas também se distanciam, pois é fundamental que a análise seja orientada pela singularidade da operação artística. Ainda que a 
obra envolva a singularidade do artista e esse seja um elemento importante de análise, é preciso lembrar que o artista não está em análise e sim sua obra. Esta é um traço da cultura que diz do seu tempo, das contingências, dos valores e ideais de sua época, bem como objeto que segue interrogando o presente.

A pesquisa entre arte e psicanálise, dessa forma, reflete sobre as condições de enunciação dos traços da cultura e da subjetividade. Objetos enigmáticos, que portam uma dialética singular, jogos significantes, paradoxais formas de dizer e esconder, são aqueles com os quais se ocupa a pesquisa em psicanálise.

O conceito de objeto a, elaborado por Jacques Lacan (1995), é fundamental para refletirmos sobre as obras de arte. Representa a condição desejante frente à ausência de respostas dos objetos, em sua condição de causa do desejo, articulado ao desejo do Outro. É um objeto furado através do qual o sujeito busca um ideal que não tem consciência, que perpassa os ideais da cultura. Tensão, conflito e obscuridade em um desconhecimento constituinte sobre o objeto, a origem do desejo por ele e seu sentido. Nesse movimento ele incita significantes, convoca o sujeito à enunciação.

Os significantes em jogo nos objetos de arte orientam as análises e a interpretação, mas não direcionam a um sentido único. A dimensão da linguagem, que perpassa a condição humana, não permite significados fixos. Ainda que sejam buscados pelos sujeitos, os sentidos não cessam de se revelar parciais. Paradoxal condição humana que da falta a ser, da precariedade, possibilita-se o ir em busca, o desejo de saber mais.

E incidentalmente não desprezemos a palavra. Afinal de contas, ela é um instrumento poderoso; é o meio pelo qual transmitimos nossos sentimentos a outros, nosso método de influenciar outras pessoas. As palavras podem fazer um bem indizível e causar terríveis feridas. Sem dúvida 'no começo foi a ação' e a palavra veio depois; em certas circunstâncias ela significou um progresso da civilização quando os atos foram amaciados em palavras. Mas originalmente a palavra foi magia - um ato mágico; e conservou muito de seu antigo poder. (Freud, 1926/1976a)

A relação da subjetividade com a linguagem, com a palavra, é uma das principais formulações da teoria de Lacan e foi inspirada na leitura da obra freudiana e da linguística de Ferdinand de Saussure. Conforme Garcia-Roza (2009), uma das ideias centrais de Saussure é o conceito de signo como sendo composto de duas partes: o significado e o significante.

Lacan vai além do que foi indicado por Saussure, propondo que o significante se sobrepõe ao significado. É importante ressaltar, 
quanto ao uso que Lacan faz de tais conceitos da linguística, que "é por meio deles que se produz a ruptura entre o significante e o significado, fazendo com que, pela interposição de um novo significante, o significante original caia na categoria de significado, permanecendo como significante latente" (Garcia-Roza, 2009, p. 189).

A partir da apresentação desses conceitos, indicamos os atravessamentos destes na dimensão da pesquisa em psicanálise e como estaremos relacionando-os com a arte. Esses fragmentos teóricos são trazidos, também, para situar minimamente por onde se inscreve o conceito de inconsciente para a psicanálise freudolacaniana, os quais colocam a linguagem como via principal de labor. Destarte, a psicanálise propõe pensar o sujeito no que ele tem de "mais efêmero e raro, junto com o que nele há de mais materialista e universal: a linguagem. Ou seja, permite defender a categoria de sujeito e ao mesmo tempo nos adverte da periculosidade filosófica que isso representa" (Dunker, 2016, p. 13).

Levamos em consideração o enunciado de Lacan (1964/1988, p. 25) de que "o inconsciente é estruturado como uma linguagem". O psicanalista Contardo Calligaris (2004), ao discorrer sobre essa formulação, chama a atenção para a distinção entre linguagem e língua. Lacan refere-se à linguagem e não à língua, sabendo que, para Saussure, esta é constituída por língua, palavra, fala e código. Dessa forma, o que se entende é que o inconsciente fala. 0 inconsciente é, portanto, a moradia do sujeito, o lugar de uma enunciação. Isso situa uma diferença importante entre a psicanálise de Freud e de Lacan: "Se de uma certa forma, caricaturalmente, um analista freudiano estaria se perguntando sobre o que o paciente está dizendo, um analista lacaniano estaria constantemente se perguntando de onde ele está falando" (Calligaris, 2004, p. 175).

O psicanalista e pesquisador Luciano Elia (2010) menciona as proposições lacanianas de que o significante pode ser separado do significado. O autor afirma que, no interjogo da materialidade dos significantes e de suas relações, os significados se produzem, o que evidencia a condição de primazia do significante. Essas elaborações são importantes para pensarmos o conceito de sujeito.

O sujeito é um operador que se impõe a nós, desde que nos coloquemos em determinada perspectiva, em determinado lugar a partir do qual interrogamos a experiência humana, seguindo os passos de Freud, que foi o primeiro a fazer isso. 0 sujeito é, portanto, sempre suposto. Não o encontramos na realidade, mas o supomos. Ou melhor, somos forçados a supôlo a partir do momento em que reconhecemos a incidência do significante na experiência humana, esse átomo de simbólico que, por não ter em si mesmo significação alguma, convoca, no 
ser vivo, quando ele é falante (ou seja, quando é habitado pelo simbólico), a resposta que se chama de sujeito. Somos forçados a supor o sujeito quando reconhecemos o significante porque na verdade é o significante (e não nós) quem supõe o sujeito. O sujeito é, pois, uma suposição do significante, que se impõe a nós. (Elia, 2010, pp. 70).

Nesse sentido, buscar os elementos significantes que situam o sujeito em determinadas posições diante do desejo e diante da cultura permite que percebamos as nuances que o situam como ser constituído e barrado pela linguagem, com toda a falta e todas as possibilidades oriundas dessa condição. No campo da pesquisa em psicanálise, ressaltamos que os elementos significantes devem ser evidenciados, para que se possa desenvolver possibilidades interpretativas que buscam densidade da singularidade em questão, suas dimensões estruturais e metapsicológicas.

A inclusão do sujeito do inconsciente diz da ética e da política da psicanálise. Conforme Lacan (1991), a ética "começa no momento em que 0 sujeito coloca a questão desse bem que buscara inconscientemente nas estruturas sociais - e onde, da mesma feita, foi levado a descobrir a ligação profunda pela qual o que se apresenta para ele como lei está estreitamente ligado à própria estrutura do desejo" (p. 97). Dessa forma, a ética não está balizada numa moral, com obrigações legais ou pautada em um suposto bem comum, mas naquilo que é mais íntimo do sujeito, mais singular, por ser o que o constitui e que, sobretudo, visa resistir aos exercícios de poder, que tendem ao assujeitamento.

\section{Dos Enlaces Criativos e Caminhos do Método}

A pesquisa em psicanálise, conforme desenvolvemos, constrói seu rigor a partir dos conceitos forjados pela clínica e que se desdobram sobre a análise da cultura, tais como: inconsciente, sujeito, objeto, significante, contingência e sintoma. Estes pressupõem um método que nos permite ter acesso a eles: a associação livre, a escuta flutuante e a análise da dinâmica da transferência. Esta perspectiva teórica e conceitual envolve uma dimensão ética e política, que tem como princípio o sujeito e as singularidades.

$\mathrm{O}$ interesse pela singularidade, pelo inconsciente, pela linguagem e pelos sintomas aproximou a psicanálise da arte. Este campo permite, de forma exemplar, aproximarmo-nos do que é mais íntimo do humano e de suas formas de dizer e mostrar. Nesse sentido, a arte fala do sujeito "mesmo que isso não se deixe capturar em palavras, em uma teoria - ou talvez graças ao fato de que isso resiste a uma teoria, justamente" (Rivera, 2017, p. 34). 
O interesse da psicanálise pela arte não é recente e podemos dizer que, no desenvolvimento de toda a teoria, observamos a importância que Freud dá à arte, inclusive fazendo questão de reiterar que o artista precede o psicanalista em relação ao conhecimento do inconsciente. É por este aspecto que esse encontro se torna tão frutífero para a teoria psicanalítica.

Freud (1910/2015b) teceu muitas articulações entre arte e psicanálise. No seu texto "Uma lembrança de infância de Leonardo da Vinci", faz uma análise do artista e de suas obras, acentuando certas características psicológicas do artista em detrimento de sua produção. No entanto, mesmo que em certos momentos tenha pendido à análise do artista, não deixou de situar questões sociais importantes, dando visibilidade a aspectos obscuros, que não eram considerados nas análises acerca da produção de Leonardo e seu valor como pintor e como cientista. Diz Freud:

"Na sua época, na qual a autoridade da igreja começava a ser confundida com a da Antiguidade e que não conhecia uma investigação sem hipóteses, ele foi o precursor, sim, um concorrente nada desprezível de Bacon e Copérnico, necessariamente isolado" (Freud, 1910/2015b, pp. 72).

As críticas de Giorgio Vasari, considerado o primeiro historiador de arte, sobre Leonardo, problematizavam que o artista não estaria agradando a Deus e aos homens por não ter feito seu dever em relação à arte. Para Freud, Leonardo certamente não fez seu dever, se comparado à arte de sua época, pois sua obra expõe certo mistério que lhe confere um valor irrepreensível. A incompreensão em relação a sua produção artística e intelectual era censurada justamente por apresentar algo de misterioso e indecifrável. Nesse sentido, destaca-se o olhar de Freud sobre o tema da estética, revelando o direcionamento do seu olhar para aquilo que aparentemente teria menor valor, ou sobre o que seria mais enigmático nas discussões sobre arte.

A arte inspirou muitos dos textos metapsicológicos freudianos. Em um encontro horizontal e profícuo, Freud reflete sobre a subjetividade, a sexualidade e o inconsciente em diálogo com Goethe, Leonardo, Michelangelo, Rilke, E.T.A. Hoffmann, Dostoiévski, entre outros poetas e artistas. Suas análises da cultura envolvem a arte, a literatura, as tragédias e os mitos. Esse encontro permite que ele aprofunde conceitualmente a análise sobre a criação, sobre as pulsões, o inconsciente, as fantasias, o brincar e suas relações com os outros e com a cultura. Freud apresenta-nos questões complexas e decisivas que decorrem do encontro com as artes (Chaves, 2015). Nesse sentido, a nova ciência recuperava a relação com a poética. 
Como bem analisa a psicanalista e pesquisadora Tânia Rivera, o diálogo com a arte vem da necessidade de que a concepção do sujeito como descentrado seja "tomada em seu sentido forte, ou seja, que assuma plenamente que ele não se delimita como indivíduo e dono de uma "subjetividade" que complementa o campo social e "objetivo" sem se confundir com ele, como acredita, de modo geral, a psicologia" (Rivera, 2017, p. 35). Nesse sentido, Freud (1930/1992c) situa a capacidade da arte de reconciliar o homem com a cultura, reforçando seus laços de pertencimento.

A teoria psicanalítica sustenta (Freud, 1915/1992b) que entre a realidade (que faz barreira ao desejo) e o mundo imaginário (que 0 "realiza") encontra-se a arte, como uma forma de intermediação. Ao aspirar por uma forma de expressão, o artista a partilha, através de sua obra, com outros sujeitos que possuem a mesma restrição inevitável a seus desejos. Nesse sentido, essa autoliberação está relacionada à retomada do conflito e não a uma vitória da satisfação pulsional.

Outra teorização freudiana fundamental para pensarmos a questão da arte é desenvolvida no texto "O estranho" Freud (1919/2014). Ao discorrer acerca da questão do estranho, parte da ideia do que causa medo e terror e evoca a etimologia dessa palavra. Em alemão, unheimliché a palavra que, no português, tomamos como estranho. Dentre os significados de unheimlich, chama a atenção de Freud o fato de que o termo porta o seu oposto: heimlich, como aquilo que é usual e familiar. Unheimliche, dessa forma, na análise freudiana, designa algo que não se sabe abordar, que causa estranheza porque traz consigo traços da ordem da familiaridade que se desconhece: "Unheimlich seria tudo o que deveria ter permanecido secreto e oculto e, no entanto, veio à luz" (Freud, 1919/2014, p. 41). Este sentimento ambivalente pertence, para Freud, ao domínio da estética. A estética, que envolve a reflexão sobre as qualidades de nosso sentir, tende a ocupar-se do belo. A psicanálise, por outra via, não se restringe às teorias sobre o belo e avança na análise sobre 0 estranho (Freud, 1919/2014).

Para a psicanálise, o sujeito se constitui em relação a uma exterioridade íntima e a arte talvez seja o campo que nos dê mais diretamente notícias dessa excêntrica operação constitutiva. É nesta direção que buscamos sustentar o encontro e a possibilidade de articulação teórica da psicanálise com a arte, contemplando o sujeito do inconsciente. Dessa forma, faz-se importante elucidar a partir de quais aspectos são desenvolvidas algumas interpretações. Assim, a questão da contingência, do contexto das obras é fundamental para articulá-las diante do tempo em que foram realizadas e, também, do que ainda permanece em questão e remete à nossa época. A obra lê a realidade, e também institui uma nova, interrogando outros tempos. 
Pensar a obra, para além do artista, significa considerar que, ao fazer tal produção não transparece apenas a singularidade do autor, mas são produzidos exemplares de um tempo e das condições de enunciação possíveis a partir de determinado contexto. O que está em questão não é uma psicopatologia do artista e sim relançar questões sobre a cultura a partir de sua obra. Esta extrapola a intenção do autor e materializa-se como um outro corpo. Assim, é fundamental pensar o caso a caso, a singularidade em jogo, analisando as condições para que o ficcional se constitua e se manifeste em uma materialidade.

Além disso, cabe considerar o encontro entre obra e pesquisador e os efeitos que se transmitem a partir da escrita. Didi-Huberman (1998), no livro "O que vemos, o que nos olha", sublinha a relação dialética de estranhamento entre aquele que olha e a obra que o interroga. Evidencia-se que, para além de olhar uma obra, somos olhados por ela, destacando a singularidade do olhar e os não-sentidos que as obras colocam em questão.

O autor defende que a obra é fruto do inconsciente, demonstrando uma complexa rede de deslocamentos e condensações. É, portanto, densa, não se deixando capturar totalmente pela linguagem. Dessa forma, Didi-Huberman (1998) busca em suas análises superar a perspectiva tautológica das imagens (nas quais as imagens valeriam por elas mesmas), procurando elementos que possam ser engendrados em possibilidades de significação para além do que se mostra. Estes desdobramentos teóricos convidam-nos a refletir sobre a espessura das imagens, a procurar outros olhares e leituras possíveis sobre as obras, relançando, portanto, o enigma que portam. Didi-Huberman (1998) teoriza sobre a importância de pensarmos a obra como corpo. Dessa forma, caberia ao analista resgatar os diálogos que ela estabelece com o outro, com a cultura, perceber suas entradas e saídas, seu volume, a especificidade da forma que revela e ao mesmo tempo ao que esconde, em um movimento de produção de sentidos. Obra fruto da incompletude que a cria e presença que se oferece ao vazio, à precariedade.

Assim, para que possamos aproximar a arte e a psicanálise, uma das questões com as quais nos deparamos é a da relação entre o ato analítico e $o$ ato criativo.

Tanto 0 ato analítico quanto 0 ato criativo buscam dar visibilidade ao vazio que suporta os objetos, revelam a incompletude constituinte dos objetos e a relação faltosa que os sujeitos estabelecem com eles. Entretanto, enquanto o ato analítico rompe com uma estrutura lógico-discursiva, 0 ato criativo dá forma a objetos, a ações que rompem com os sentidos (Marsillac, 2018, pp. 272). 
Entendemos que a arte tem o papel de colocar em questão os sentidos, não apenas através de uma discussão acerca da obra, mas de uma dinâmica capaz de transformar a relação com o mundo e que nos reposiciona enquanto sujeitos de desejo.

A ênfase da psicanálise na questão do desejo pode ser entendida como um convite ao movimento e à deriva, uma vez que o desejo não se nomeia ou localiza, mas sim se esquiva e ressurge em outra parte (Rivera, 2005). Portanto, as aproximações possíveis entre pesquisas envolvendo a arte e a psicanálise promoverão não a sua resolução ou entendimento, mas a recolocação das questões, sob novas perspectivas. Isso está articulado com os preceitos da psicanálise. Ao construirmos certos caminhos, sabemos que a falta estará em questão e é ela que possibilita a realocação do desejo.

\section{Considerações finais}

De acordo com o psicanalista Didier-Weill (1997), um dos modos que, na atualidade, podemos perceber o mal-estar na civilização, seria a difusão de um saber científico anônimo, saber sem sujeito, que culmina com um olhar onipotente sobre o homem. Ao saber tudo, de modo absoluto, dá-se o aniquilamento do sujeito do inconsciente. A psicanálise, em uma dimensão ética, surge na perspectiva de colocar em questão o sujeito do inconsciente. $O$ ato criativo é considerado, nessa perspectiva, como uma possibilidade de recolocar o inaudível, o invisível, como uma forma de permitir que o incógnito do ser humano tenha lugar.

Nesse sentido, refere o psicanalista e pesquisador Sousa (2015), quanto a Freud: "Seu método clínico colocou em cena a possibilidade de termos consciência sobre a estilística daquela que talvez seja a obra mais fundamental que construímos: as formas de nosso viver" (Sousa, 2015, p. 321). Logo, a intrínseca relação entre arte e psicanálise parte dessa troca em que obra e vida tanto se confundem quanto se abrem a outras possibilidades interpretativas.

O diferencial da leitura psicanalítica sobre as obras de arte envolve o encontro com o sujeito do inconsciente, dimensão não-toda e pulsante da subjetividade, radicalmente singular. Sem a pretensão de conferir um fechamento ao enigma que os traços da cultura nos interpõem, a interpretação sustentada pela psicanálise busca sublinhar os diálogos operados pela obra com o laço social, através da singularidade do artista. No ato analítico, o estranho convoca o olhar e as interrogações, a repetição e o deslocamento dos significantes em jogo permitem situar contingências. A obra como vestígio interroga quem a olha, questiona a história que a atravessa e, paradoxalmente, reescreve-a, conferindo uma poética do viver. 
Concordamos com Lacan (1997) ao sustentar que a realidade se constitui enquanto ficção. Assim, percebemos que o movimento da produção de conhecimento em psicanálise recoloca em movimento o ficcional que constitui a condição humana no mundo. Afinal, esta é a verdade que a psicanálise sustenta. Recuperar esses saberes na produção de conhecimento contemporâneo sobre a cultura permitenos avançar frente a contextos que tendem a desconsiderar 0 inconsciente que nos habita e nos move, em busca das certezas do ser.

\section{Referências}

Aguiar, F. (2006). Questões epistemológicas e metodológicas em psicanálise. Jornal de Psicanálise, 29(70), 105-131. Recuperado de

http://pepsic.bvsalud.org/scielo.php?script=sci_arttext\&pid=S0 103-58352006000100007

Brites, B., \& Tessler, E. (Orgs.). (2002). O meio como ponto zero: Metodologia da pesquisa em artes plásticas. Porto Alegre: Editora da Universidade/UFRGS.

Calligaris, C. (2004). O inconsciente em Lacan. Arquivo Charles Lang. Recuperado de https://pt.scribd.com/doc/97934279/OInconsciente-Em-Lacan-Contardo-Calligaris

Chaves, E. (Trad.). (2015). Obras incompletas de Sigmund Freud: Arte, literatura e os artistas. Belo Horizonte: Autêntica.

Didi-Huberman, G. (1998). O que vemos, o que nos olha. São Paulo: Editora 34.

Didi-Huberman, G. (2017). Diante do tempo: História da arte e anocronismo das imagens. Lisboa: Orfeu negro.

Didi-Huberman, G. (2015). Invenção da Histeria: Charcot a iconografia fotográfica da Salpêtriere. Rio de janeiro: Contraponto.

Didier-Weill, A. (1997). O artista e o psicanalista questionados um pelo outro. In A. Didier-Weill, Nota Azul: Freud, Lacan e a arte (pp. 19-36). Rio de Janeiro: Contra capa.

Duchamp, M. (1986). O ato criador. In G. Battcock (Org.), A nova arte (2a ed., pp. 71-74) São Paulo: Perspectiva. (Obra original publicada em 1965)

Dunker, C. I. L. (2016). A teoria lacaniana do sujeito: Uma apresentação comparativa. In C. I. L. Dunker, Por que Lacan? (pp. 143-178). São Paulo: Zagodoni, 143-178.

Dunker, C. I. L. (2017, Maio 03). A psicanálise como ciência [Web log post]. Blog da Boitempo: Notícias. Recuperado de http://www.ip.usp.br/site/noticia/a-psicanalise-como-ciencia/ 
Elia, L. (2000). Psicanálise: Clínica e pesquisa. In S. Alberti, L. Elia (Orgs.), Clínica e Pesquisa em Psicanálise (pp. 19-36). Rio de Janeiro: Rios Ambiciosos.

Elia, L. (2010). O conceito de sujeito (3a ed.). (Psicanálise passo-apasso, Vol. 50). Rio de janeiro: Jorge Zahar. Recuperado de http://files.pedagogiahorizonte.webnode.com/20000012327ebb28e7e/O-conceito-de-sujeito-2.pdf

Freud, S. (1976a). A questão da análise leiga. In Edição standard brasileira das obras psicológicas completas de Sigmund Freud (Vol. 20, pp. 209-293). Rio de Janeiro: Imago. (Obra original publicada em 1926)

Freud, S. (1976b). Os instintos e suas vicissitudes. In Edição Standard Brasileira das obras completas de Sigmund Freud (Vol. 14, pp. 137-162). Rio de Janeiro: Imago. (Obra original publicada em 1915)

Freud, S. (1992a). Consejos al medico sobre El tratamiento psicoanalítico. In Obras completas de Sigmund Freud, (Vol. 12, pp. 111-120.). Buenos Aires: Amorrortu. (Obra original publicada em 1912)

Freud, S. (1992b). Lo inconciente. In Obras completas de Sigmund Freud (Vol. 24, pp. 161-214). Buenos Aires: Amorrortu. (Obra original publicada em 1915)

Freud, S. (1992c). El malestar en la cultura. In Obras Completas de Sigmund Freud (Vol. 21, pp. 57-140). Buenos Aires: Amorrortu. (Obra original publicada em 1930)

Freud, S. (1992d). Nuevas conferencias de introducción al psicoanálisis. In: Obras Completas de Sigmund Freud (Vol. 22, pp. 5-168). Buenos Aires: Amorrortu. (Obra original publicada em 1933[1932])

Freud, S. (2014). O estranho. In I. Pereira (Org.), Escritos sobre literatura (S. Krieger, Trad., pp. 33-77). São Paulo: Hedra. (Obra original publicada em 1919)

Freud, S. (2015a). O poeta e o fantasiar. In Obras incompletas de Sigmund Freud: arte, literatura e os artistas (E. Chaves, Trad.). Belo Horizonte: Autêntica. (Obra original publicada em 1908)

Freud, S. (2015b). Uma lembrança de infância de Leonardo da Vinci. In Obras Incompletas de Sigmund Freud: Arte, literatura e os artistas (E. Chaves, Trad.). Belo Horizonte: Autêntica. (Obra original publicada em 1910)

Freud, S. (2015c). Obras incompletas de Sigmund Freud: arte, literatura e os artistas. (E. Chaves, Trad.). Belo Horizonte: Autêntica Editora. (Obra original publicada em 1856-1939)

Garcia-Roza, L. A. (2009). O inconsciente. In L. A. Garcia-Roza, Freud e o Inconsciente (pp. 168-195). Rio de Janeiro: Jorge Zahar.

Jameson, F. (1992). O Inconsciente político: A narrativa como ato socialmente simbólico. São Paulo: Atica. 
Kapinist, E., \& Roudinesco, E. (Diretoras). (1997). A invenção da psicanálise [Documentário]. França: GNT.

Lacan, J. (1988). O seminário, livro 11: Os quatro conceitos fundamentais da psicanálise. Rio de Janeiro: Jorge Zahar. (Obra original publicada em 1964)

Lacan, J. (1995). O seminário, livro 4: A relação de objeto. Rio de Janeiro: Jorge Zahar.

Lacan, J. (1997). O seminário, livro 7: A ética da psicanálise. Rio de Janeiro: Jorge Zahar.

Lacan, J. (1998). A ciência e a verdade. In J. Lacan, Escritos (pp. 869-892). Rio de Janeiro: Jorge Zahar.

Lacan, J. (2003). Proposição de 9 de outubro de 1967 sobre o psicanalista da Escola. In J. Lacan, Outros Escritos (pp. 248264). Rio de Janeiro: Jorge Zahar. (Obra original publicada em 1967)

Lacan, J. (2016). Os não-tolos vagueiam. Bahia: Espaço Moebius de psicanálise.

Loparic, Z. (1991). Um olhar epistemológico sobre o inconsciente freudiano. In F. Knobloch (Org.), $O$ inconsciente (pp. 43-58). Várias leituras. São Paulo: Escuta.

Marsillac, A. L. M. (2018). Aberturas utópicas: Arte, política e psicanálise. Curitiba: Appris.

Rivera, T. (2005). Arte e psicanálise (2a ed.). Rio de Janeiro: Jorge Zahar.

Rivera, T. (2017). Dossiê Arte e Psicanálise: o avesso do imaginário. Revista Cult, 20(225), 34-37.

Rosa, M. D. (2004). A pesquisa psicanalítica dos fenômenos sociais e políticos: Metodologia e fundamentação teórica. Revista Mal Estar e Subjetividade, 4(2), 329-348. Recuperado de http://pepsic.bvsalud.org/scielo.php?script=sci_arttext\&pid=S1 518-61482004000200008\&lng=pt\&tlng=pt

Roudinesco, E. (2009). Medicina, Psiquiatria e Psicanálise: Semiologia do sujeito. In E. Roudinesco, Em defesa da psicanálise: ensaios e entrevistas (pp. 215-224). Rio de Janeiro: Zahar.

Rubin, C. E. (2011). Freud na Salpêtrière: Algumas considerações sobre o "informe sobre meus estudos em Paris e Berlim". Revista Digital AdVerbum, 6(2), 159-166. Recuperado de http://www.psicanaliseefilosofia.com.br/adverbum/vol6_2/06_0 2_04freudnasalpetriere.pdf

Sousa, E. L. A. (2015). Faróis e enigmas: Arte e psicanálise à luz de Sigmund Freud. In Obras Incompletas de Sigmund Freud: Arte, literatura e os artistas (pp. 317-331). Belo Horizonte: Autêntica Editora. 


\section{Endereço para correspondência}

\section{Ana Lúcia Mandelli de Marsillac}

Universidade Federal de Santa Catarina

Departamento de Psicologia - CFH

Campus Universitário Reitor João David Ferreira Lima, s/no sala 213 Bloco D, Trindade, CEP 88040-970, Florianópolis - SC, Brasil

Endereço eletrônico: 2206ana@gmail.com

\section{Gerusa Morgana Bloss}

Servidão João Basílio da Cunha, 585, Ribeirão da Ilha, CEP 88064-032, Florianópolis - SC, Brasil

Endereço eletrônico: gebloss@gmail.com

\section{Thiciara Mattiazzi}

Servidão Manoel João Pires, 80, Campeche, CEP 88063-258, Florianópolis - SC, Brasil

Endereço eletrônico: mattiazzithiciara@gmail.com

Recebido em: 07/01/2019

Reformulado em: 11/07/2019

Aceito em: 04/10/2019

\section{Notas}

* Psicóloga, Psicanalista, Pós-doutoranda na Universidade Nova de Lisboa, Dra. Artes Visuais - História, teoria e crítica UFRGS.

** Psicóloga pela Universidade Federal de Santa Maria (2017). Mestranda em Psicologia com ênfase em Psicologia Social e Cultura - Estética, Processos de Criação e Política pela Universidade Federal de Santa Catarina (2017).

*** Psicóloga, Psicanalista, Mestranda em Psicologia com ênfase em Práticas Culturais e Processos de Subjetivação - Relações Éticas, Estéticas e Processos de Criação pela Universidade Federal de Santa Catarina (2017).

Financiamento: Coordenação de Aperfeiçoamento Pessoal de Nível Superior CAPES - Código de financiamento 001.

Este artigo de revista Estudos e Pesquisas em Psicologia é licenciado sob uma Licença Creative Commons Atribuição-Não Comercial 3.0 Não Adaptada. 